\title{
PSYCHOSOCIAL DISTRESS AS A RISK FACTOR OF ASTHMA MORTALITY
}

\author{
Yury E. Razvodovsky \\ Grodno State Medical University, 230009, Grodno, str. Gorky 80, Belarus
}

received: 28.10.2009; $\quad$ revised: 1.2.2010;

accepted: 1.3 .2010

\section{SUMMARY}

Background: Asthma is a mayor public health problems and its prevalence has risen in recent decades world wide. Various explanations have been proposed to explain this trend including air pollution, aeroallergens, diet, infections and tobacco smoke. However, focus on biological risk factors has not fully explained this trend. A mounting body of research evidence suggests that psychosocial stress is likely to be a factor contributing to the development of asthma. The aim of the present study was to estimate the effect of psychosocial distress on asthma mortality rate at the aggregate level.

Subjects and methods: Trends in age-adjusted, sex-specific suicide (as an integral indicator for psychosocial distress) and asthma mortality rate in Russia from 1975 to 2005 were analyzed employing an ARIMA analysis in order to asses bivariate relationship between the two time series.

Results: Time series analysis indicates the presence of statistically significant association between the two time series both for males and females.

Conclusion: The findings of the present study add to the growing number of studies linking psychosocial distress to asthma expression and mortality. This paper presents new epidemiological evidence that supports psychosomatic concept of asthma.

Key words: asthma - stress - mortality - time series analysis - Russia

\section{INTRODUCTION}

Asthma is estimated to affect 300 million people world-wide and causes 0.25 million deaths annually (Masoli et al. 2004, Anderson 2005). Its prevalence has risen in recent decade's world wide with an expected increase to 400 million by 2025 (Bosquet et al. 2005). Various explanations have been proposed to explain this trend including air pollution, aeroallergens, diet, infections and tobacco smoke (Brauer 2007, Litonjua 2008, Rage et al. 2009). However, focus on environmental and biological risk factors has not fully explained this phenomenon. The recent research evidence has led investigators to reconsider the role of psychosocial stress in the genesis and expression of asthma (Wright 1998, Rietveld et al. 2000, Klinnert 2003, Chen \& Miller 2007). Whereas earlier psychosomatic concept has supported a role for psychosocial stress in exacerbation among those with existing disease, growing evidence suggests a role for stress in the etiology of asthma as well. In particular, several methodologically sound studies have reported an association between stressful life events and both the onset and exacerbation of established disease (Harrison 1998, Cudy \& Li 2001, Drake et al. 2008). Recent investigations have contributed evidence concerning the relationship between depression/anxiety and risk of asthma (Bender 206, Scoft 2007, Kewalramani 2008). It was highlighted that the association exists between asthma and post-traumatic stress disorder (PTSD) even after adjustment for potential confounders such as cigarette smoking, obesity and socioeconomic status (Goodwin et al. 2007). These data are especially relevant in the light of clinical studies suggesting the benefit of psychotherapy in treating asthmatic patients (Kelner 1975, Lehrer 2008).

A growing research and empirical evidence suggests that psychosocial factors may be important in asthma death. Rea and colleagues has shown that psychosocial problems (alcohol abuse, depression, recent bereavement) recorded in the notes were significantly more common in patients who died than in controls who had required admission to hospital (Rea et al. 1986). Similarly, Wareham et al. (1998) highlighted that psychosocial factors listed as social isolation, abuse as a child, marital and legal problems and alcohol abuse have contributed to the deaths of $71 \%$ patients with asthma in Norfolk. A more recent community based case-control study of 533 asthma deaths cases and 533 hospital controls in seven regions of Britain (1994-98) reported that $85 \%$ of cases and $86 \%$ of controls had psychosocial problems (Sturdy et al. 2002). After adjustment for potentially confounders three psychosocial factors were associated with increased risk of deaths: psychosis, financial/employment problems, learning difficulties.

Taken together, this evidence strongly supports an association between asthma and stress, although precise mechanisms underling this association remain poorly understood. Hypothetically stress may impact asthma morbidity through the interactions between behavioral, neuroimmunological and endocrine mechanisms. Stress 
can stimulate production of cytokines that lead to airway inflammation and increase vulnerability to upper respiratory infections that can trigger exacerbation (Freiri 2003, Brydon 2009). Stress also can result in cumulative wear and tear (allostatic load) and suppressed immune function (Chen \& Miller 2007). Social and psychological risk factors are closely related because social factors can increase psychological stress. It was shown that lower level of family support affect asthma symptoms and pulmonary function through biological pathways, such as allergic inflammation, whereas community factors influenced asthma symptoms through behavioral pathway, such a high smoking rate (Chen et al. 2007a).

Although psychosocial distress seems to be important contributor to the burden of asthma morbidity and mortality worldwide, there has been no systematic research on stress-asthma relations at the population level. The aim of the present study was to address this particular deficit by using aggregate-level data on asthma mortality and suicide (as an integral indicator for psychosocial distress) in Russia from 1975-2005.

\section{SUBJECTS AND METHODS}

The data on age-adjusted sex-specific suicide and asthma mortality rates per 1000,000 of residents are taken from the Russian vital statistics registration system. The statistical analysis was performed using the package "Statistica". It is generally agreed that bivariate correlations between two raw time-series are spurious due to common sources of trends and autocorrelation (Norstrom \& Skog 2001). Therefore in order to reduce the risk of obtaining a spurious relation between two variables that have common trends, the trends should be removed by means of a differencing procedure: $\nabla \mathrm{x}_{\mathrm{t}}=\mathrm{x}_{\mathrm{t}}$ - $\mathrm{x}_{\mathrm{t}-1}$ This means analyzing annual changes rather than raw data. This technique for time series analysis has been suggested by Box and Jenkins and often referred to as ARIMA (autoregressive integrated moving average) model (Box \& Jenkins 1976). We used the ARIMA model to estimate the relationship between the time series suicide and asthma mortality rates in this paper.

\section{RESULTS}

Trends in sex-specific suicide and asthma mortality rates are presented in Figures 1-2. As can be seen, both suicide and asthma time series for males and females fluctuated over the period: decreased in the mid-1980s, jumped dramatically in the early 1990s and than started to decrease. It should be noted that the pattern male suicide and asthma mortality rates is quite similar over time series, while there is a substantial difference between the female mortality trends. In particular, the increase in asthma mortality rate in the early 1990s was substantially greater for men: between 1986 and 1994 the male rate jumped by $97.3 \%$ (from 55.2 to 108.6 per 1 million populations), while the female rate increased by $61.1 \%$ (from 35.0 to 56.4 per million populations).

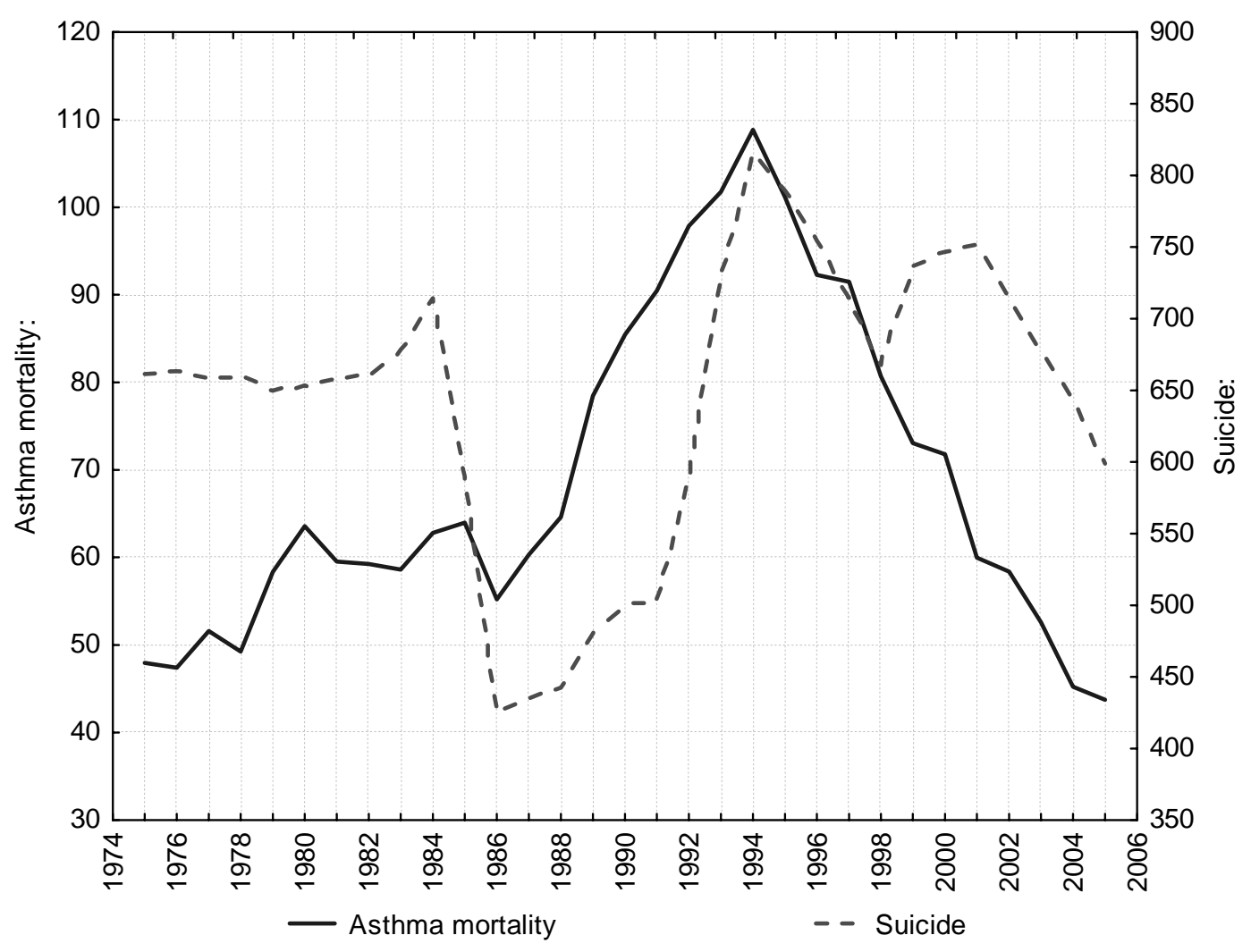

Figure 1. Trends in suicide and asthma mortality for males in Russia between 1975 and 2005 


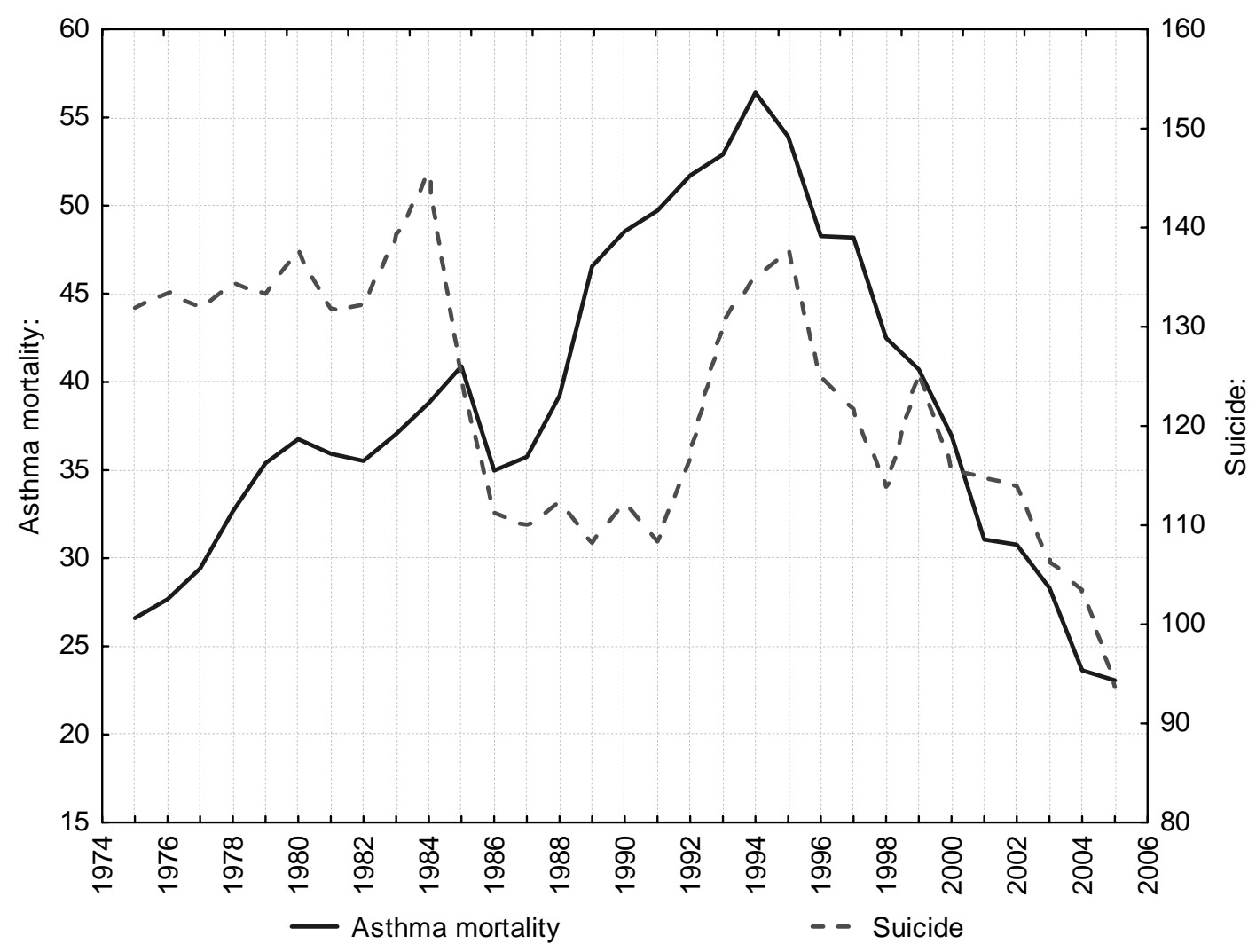

Figure 2. Trends in suicide and asthma mortality for females in Russia between 1975 and 2005

It is important to point out that the male suicide rate was significantly higher than the female rate with a rate ratio of 5.0 in 1975 increasing to 6.4 by the 2005 . Although reports from various countries indicate that suicide rates for male are much higher than for females (Liu at al. 2009), no satisfactory explanation for this phenomenon has been suggested. As can be seen from Figures 1-2 there is linear and S-shape trends in the time series. These trends were removed by means of firstorder differencing procedure. After pre-whitening the cross-correlations between suicide and asthma mortality time series were inspected. The outcome indicated statistically significant cross-correlation between suicide and asthma mortality trends at zero lag for males $(r=0.49 ; \mathrm{SE}=0.18)$ and females $(\mathrm{r}=0.37 ; \mathrm{SE}=0.18)$.

\section{DISCUSSION}

Understanding the reasons of dramatic grows in asthma mortality in the early 1990s in Russia is very important from public health perspective. To address this issue it is necessary to focus on the social and economic changes that have occurred in Russia in the last decades. Following the collapse of the Soviet Union by the end 1991 and introduction of "shock therapy" economic reforms, Russian citizens have experienced psychosocial distress. The growing political instability and economic collapse had serious implications, including increase in mortality rate (Stickley et al. 2009). In particular, the transition has had a dramatic impact on suicide mortality, which is often referred as an indicator of psychosocial stress and anomie (Pridemore 2006, Razvodovsky 2009). It seems that males were most vulnerable to the stressful experience resulting from abrupt socioeconomic changes, political instability, unemployment and impoverishment. The impact of acute socioeconomic transition has been exacerbated by a lack of social cohesion, erosion of social capital and rising income inequality. Walberg and colleagues found that the fall in male life expectancy at birth and mortality increase were greater in Russian regions that in the 1990s experienced larger shocks due to socioeconomic reform, higher income inequality and unemployment (Walberg et al. 1998). In another study, the psychosocial stress, measured by shift in the Gini coefficient, explained the greatest part of the variance in mortality for the European regions of Russia (Cornia \& Poniccia 2000). The idea, that social deprivation and inequality are the important determinants of asthma mortality is supported by the research evidence from other settings. In New Zealand asthma mortality was more than twice higher in the lower social class areas than in the higher social class areas (Jackson 1988). In South Africa asthma deaths were four to five times higher in the colored population than in white subjects (Ehrlich \& Bourne 1994). In the USA asthma morbidity disproportionately impacts on poor urban minority populations (Marder et al. 1992). The negative association between poverty/ethnic minority status and asthma morbidity may be due to different exposure to 
life stressors (Drake et al. 2008). So, research evidence points to psychosocial distress as a potentially important factor of dramatic grows in asthma mortality in the early 1990s in Russia. The shock in the early 1990s was followed by a period of relative improvement and stability in the second half of the decade. In fact, trends in asthma mortality in the 1990 s fit a typical stressrelated pattern: dramatic grows in the early 1990s (the acute stress) and decrease in the second half of the decade (the stage of adaptation).

Here we should address the potential limitations of this study. It might be the case that suicide and asthma mortality trends are being influenced by the confounding variables. We have reason to believe that the profound mortality fluctuation in Russia may be related to alcohol consumption (Stickly et al. 2009). The effect of alcohol on asthma has been studied extensively with conflicting results (Cudy \& Li 2001, Sohn et al. 2001, Vally et al. 2001, Kewalramani et al. 2008). In a questionnaire based study Ayres and Clark (1998) reported that $32.1 \%$ of patients experienced wheezing after alcohol consumption, while $23.2 \%$ showed a reduction of symptoms. On the other hand, alcoholinduced asthma has been observed among $51.4 \%$ of Japanese asthmatic patients (Fujimura \& Myou 2001). In general, alcoholic drinks, and particularly wines, appear to be triggers for asthma responses. In this contexts it is important to note that substantial decrease in asthma mortality in Russia corresponds with the antialcohol campaign of 1985-1988, witch significantly reduced alcohol availability.

Many scholars believe that alcohol has played an important role in the fluctuation of suicide mortality rate in Russia during the last decades (Makinen 2000, Pridemore 2006, Nemtsov \& Razvodovsky 2008). This hypothesis is based on the positive aggregate-level association between alcohol consumption and suicide rates. In his time-series analysis data for the period 1965-1999, Nemtsov (2003) has reported that a 1-liter increase in alcohol consumption is expected to increase suicide by $12 \%$ for the total population ( $13 \%$ for men and $6 \%$ for women). Several researchers have argued that psychosocial distress resulting from the "shock therapy" economic reform and sudden collapse of the Soviet paternalist system was the main determinant of the increase in alcohol consumption and suicide mortality crisis in Russia in the 1990s (Leon \& Shkolnikov 1998).

Another potential confounder of stress-asthma association is smoking. In patients with asthma, smoking has been associated with accelerated decline in pulmonary function, poor disease control and reduced responsiveness to corticosteroids (Ulrik \& Lange 2001, Boulet 2008). A further potential bias in the study is that other risk factors for asthma such as diet and pollution were not included in the statistical model. Trafficrelated air pollution has been linked to increased respiratory symptoms, increased asthma-related hospitalizations, and the diagnosis of asthma (Brauer et al. 2007). Experimental exposure to markers of trafficrelated air pollution such as diesel exhaust particles or nitrogen dioxide increases levels of inflammatory markers relevant to asthma (Pourazar et al. 2004). It seems that there is interactive effect between psychosocial stress and environmental pollution: stress increases susceptibility to pollution, and chronic pollution expose could heighten response to stress (Selgrade et al. 2006, Chen et al. 2007b). Recently Clougherry (2007) and colleagues highlighted that the risk of asthma incidence was elevated as residential traffic-related air pollution exposure increased, but only among children who had high levels of chronic stress (indicated by exposure to violence).

It is likely that increase in asthma mortality in Russia in the 1990s is a consequence of deterioration in the quality of health care system, following the collapse of Soviet Union in late 1991. As command economy collapsed, the public health system faced a financial crisis. Left without proper funding, health care system was unable to maintain needed level of medical care (Field 2005). The main evidence is from deaths among patients suffering from diabetes. It was reported that deaths from diabetes at age 50 increased about eightfold in the 1990s in many former Soviet countries (Andreev at al. 2003). Possible explanation for this rise in deaths from diabetes was suggested in study carried out in Ukraine, where it was found that patients experienced a disruption in supplies of insulin and were unable to obtain specialized care when complications arose (Telishevska at al. 2001).

The present analysis seems to indicate that the interpretation of the trends in asthma mortality in Russia during the last decades is complex because of many factors involved. Therefore, further research is necessary to quantify the contribution of various risk factors to the asthma morbidity and mortality.

\section{CONCLUSION}

The results of the present study suggest a positive aggregate level association between suicide and asthma mortality rates in Russia between 1975 and 2005 and support the hypothesis that psychosocial distress is a risk factor of asthma at the individual level. Stress can affect health directly through neuroimmunological mechanisms, or via unhealthy behavior, most notably excessive alcohol and tobacco consumption. The outcomes of this study also support the psychosomatic concept of asthma.

\section{REFERENCES}

1. Anderson HR: Prevalence of asthma. British Medical Journal 2005; 330:1037-1038.

2. Andreev EM, Nolte E, Shkolnikov VM, Varavicova E \& McKee M: The evolving pattern of avoidable mortality in Russia. International Journal of Epidemiology 2003; $32: 437-446$. 
3. Ayers JG \& Clark TJH: Alcoholic drinks and asthma: a survey. Br J Dis Chest 1983; 77:370-375.

4. Bender BG: Risk taking, depression, adherence, and symptom control in adolescents and young adults with asthma. // American Journal Respiratory Critical Care Medicine 2006; 173:953-957.

5. Bosquet J, Bosquet DJ, Godard P \& Daures JP: The public health implications of asthma. Bull World Health Org 2005; 83:548-554.

6. Boulet LP, FitzGerald JM, McIvor RA, Zimmerman $S$ \& Chapman KR: Influence of current or former smoking on asthma management and control. Can Respir J 2008; 15:275-279.

7. Box GEP \& Jenkins GM: Time Series Analysis: forecasting and control. London. Holden-Day Inc, 1976

8. Brauer M, Hoek G, Smith HA, de Jongste JC, Gerritsen J \& Postma DS: Air pollution and development of asthma, allergy and infections in a birth cohort. Eur Respir 2007; 29:879-888

9. Brydon L, Walker C, Wawrzysniak A, Whitehead D, Okamura H \& Yajima J: Synergic effects of psychological and immune stressors on inflammatory cytokine and sickness responses in humans. Brain Behav Immun 2009, 23:217-224.

10. Chen E, Chim LS, Strunk RC \& Miller GE: The role of the social envioronment in children and adolescents with asthma. Am J Resp Crit Care Med 2007a; 176:644-649.

11. Chen $E \&$ Miller GE: Stress and inflammation in exacerbation of asthma. Brain Behaw Immun 2007b; 21 : 993-999.

12. Chen E, Schreier HMC, Strunk R \& Brauer M.: Chronic traffic-related air pollution and stress interact to predict biologic and clinical outcomes in asthma. Environ Health Perspect 2008; 116:970-975.

13. Clougherty JE, Levy JI, Kubzansky LD, Ryan LD, Suglia $S F$, Canner MJ \& Wright RJ: Synergistic effects of trafficrelated air pollution and exposure to violence on urban asthma etiology. Environ Health Perspective 2007; 115:1140-1146.

14. Cornia GA \& Poniccia P: The transition mortality crisis: evidence, interpretation and policy response. In: The mortality crisis in transitional economies. Edited by: Cornia G.A., Poniccia P. Oxford: Oxford University Press. 2000, 4-37.

15. Cudy $R \& L i G$ : The role of alcohol in asthma: a review of clinical and experimental studies. The American Journal of Emergency Medicine 2001; 19:501-503.

16. Drake KA, Galanter JM \& Burchand EG: Race, ethnicity and social class and the complex etiologies of asthma. Pharmacogenomics 2008; 9:453-462.

17. Ehrlich RI \& Bourne DE: Asthma deaths among colored and white South Africans: 1962 to 1988. Respir Med 1994; 88:195-202.

18. Field MG: A comment on the Russian health crisis. Eurasian Geography and Economics 2005; 46: 5.

19. Freiri M: Neiroimmunology and inflammation: implications for therapy of allergic and autoimmune disease. Annals of Allergy, Asthma, and Immunology 2003; l):3440.

20. Fujimura $M$ \& Myou S: Alcohol-induced asthma. International Medicine 2001; 40:557-559.
21. Gilmour MI, Jaakkola MS, London SL, Nel AE \& Rogers CA: How exposure to environmental tobacco smoke, outdoor air pollutants, and increased pollen burdens influences the incidence of asthma. Environmental Health Perspectives 2006; 114:627-633.

22. Goodwin RD, Fisher MF \& Goldberg J: A twin study of post-traumatic stress symptoms and asthma. Am J Resp Clin Care Med 2007; 176:983-987.

23. Harrison BDW: Psychosocial aspects of asthma in adults. Thorax 1998; 53:519-525.

24. Jackson GP: Asthma mortality by neighborhood of domicile. NZ Medical Journal 1988; 101: 593-595.

25. Kelner R: Psychotherapy in psychosomatic disorders: a survey of controlled studies. Arch Gen Psyhiatry 1975; 32:1021-1028.

26. Kewalramani A, Bollinger ME \& Postolache TT: Asthma and alcohol. Int J Child Hum Dev 2008; 1: 115-123.

27. Kewalramani A, Bollinger ME, Postolache TT: Asthma and mood disorders. Int J Child Health Hum Dev 2008; 1:115-123.

28. Klinnert MD: Evaluating the effects of stress on asthma: a paradoxical challenge. // European Respiratory Journal. 2003; 22:574-575.

29. Lehrer PM, Karavidas MK, Lu SE, Feldman J, Kranitz L \& Abraham S: Psychological treatment of comorbid asthma and panic disorders. J Anxiety Disorders 2008; 2:671-683.

30. Leon DA \& Shkolnikov VM: Social stress and the Russian mortality crisis. JAMA 1998; 79: 790-791.

31. Litonjua AA: Dietary factors and the development of asthma. Immunol Allergy Clin North Am 2008; 28:603629.

32. Liu KY, Chen EYH, Cheung ASZ, Yip PSF: Psychiatric history modifies the gender ratio of suicide: an East and West comparison. Social Psychiatry Psychiatric Epidemiology 2009; 44: 130-134.

33. Makinen IH: Eastern European transition and suicide mortality. Social Science \& Medicine 2000; 51: 14051420.

34. Marder D, Targonski P, Orris P, Persky $Y \&$ Addington $W$ : Effect of racial and socioeconomic factors on asthma mortality in Chicago. Chest 1992; 101 (Suppl):426-429.

35. Masoli M, Fabian D, Holt $S$ \& Breasley R: The global burden of asthma: executive summary of the GINA Dissemination Committee report. Allergy 2004; 59:469478.

36. Nemtsov $A V$ \& Razvodovsky YE: Alcohol situation in Russia, 1980-2005. Social and Clinical Psychiatry 2008; 2:52-60.

37. Nemtsov AV: Suicide and alcohol consumption in Russia, 1965-1999. Drug and Alcohol Dependence 2003: 1: 161 168.

38. Norstrom $T$ \& Skog OJ: Alcohol and mortality: methodological and analytical issue in aggregate analysis, Addiction 2001; 96:5-17.

39. Pourazar J, Frew AJ, Helleday R, Kelly FJ, Wilson $S$ \& Sandstrom T: Diesel exhaust exposure enhances the expression of $I K-13$ in the bronchial epithelium of healthy subjects. Respir Med 2004; 98:821-825.

40. Pridemore WA: Heavy drinking and suicide in Russia. Social Forces2006; 85:413-430. 
41. Rage E, Siroux V, Kunzil N, Pin I, Kauffman F: Air pollution and asthma severity in adults. Occup Environ Med 2009; 66:182-188.

42. Razvodovsky YE: Suicide and fatal alcohol poisoning in Russia, 1956-2005. Druds: education, prevention and policy 2009; 16:127-139.

43. Rea HH, Scragg R, Jackson R, Beaglehole R, Fenwick J \& Sutherland DC: A case-control study of deaths from asthma. Thorax 1986; 41:833-839.

44. Rietveld $S$, Everaerd $W$ \& Creer T: Stress-induced asthma: a review of research and potential mechanisms. Clin Exp allergy 2000; 30:1058-1066.

45. Scott KM, Von Korf MV, Ormel J, Zhang M, Bruffaerst $R$ \& Alonso J: Mental disorders among adults with asthma: results from the world mental health surveys. Gen Hosp Psychiatry 2007; 29:123-133.

46. Selgrade MJK, Lemanske RF, Gilmour MI, Lucas M, ward $M D W$ \& Henneberger PK: Induction of asthma and the environment: What we known and need to know. Environmental Health Perspective 2006; 114:615-619.

47. Sohn SW, Chang YS, Lee JY, Jung JW, Kim SH \& Cho SH: Two cases of alcohol-induced asthma. J Asthma Allergy Clin Immunol 2001; 21:1201-1205.

48. Stickley A, Razvodovsky YE \& McKee M: Alcohol mortality in Russia: a historical perspective. Public Health 2009; 123:20-26.

49. Sturdy PM, Victor CR, Anderson HR, Bland JM, Butland $B K \&$ Harrison BDW: Psychological, social and health behavior risk factors for deaths certified as asthma: a national case-control study. Thorax 2002; 2002:10341039.

50. Telishevska $M$, Chenet $L$ \& McKee M: Toward an understanding of the high death rate among young people with diabetes in Ukraine. Diabetic Medicine 2001; 18: 3-9.

51. Ulrik CS \& Lange P: Cigarette smoking and asthma. Monaldi Arch Chest Dis 2001; 56:349-353.

52. Vally H, Deklerk $N$ \&Thompson PJ: Alcoholic drinks: important triggers for asthma. J Allergy Clin Immunol 2000; 105: 462-464.

53. Walberg $P$, McKee $M$, Shkolnikov $V$, Chenet $K \&$ Leon D: Economic changes, crime, and mortality crisis in Russia: regional analysis $B M J$ 1998; 17:312-318.

54. Wareham NJ, Harrison BDW, Jenkins PJ, Nicholls $J$ \& Stableforth DE: A district confidential enquiry into deaths due to asthma. Thorax 1993; 48:1117-120.

55. Wright RJ, Rodrigues $M \&$ Cohen S: Review of psychosocial stress and asthma: an integrated biopsychosocial approach. Thorax 1998; 53:1066-1074.

\section{Correspondence:}

Yury E. Razvodovsky

Grodno State Medical University

230009, Grodno, str. Gorky 80, Belarus

E-mail: razvodovsky@tut.by,yury_razvodovsky@yahoo.com 